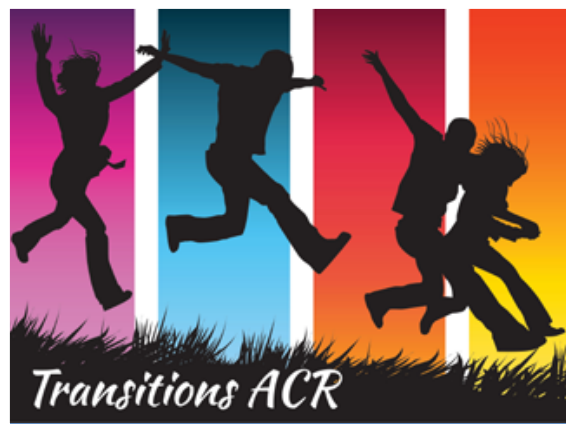

Volume 17, Issue 15

\title{
Before a Mental Health Grisis Hits: Creating a Family Safety Plan
}

\section{What Is a Family Safety Plan?}

A Family Safety Plan is a tool created collaboratively with your loved one with lived experience of mental health condition(s), family members, medical staff and friends. It's your "playbook" of the best ways to minimize or divert a mental health crisis. The plan is prepared when your loved one is stable and can fully contribute. The goal of the plan is to identify possible triggers for a mental health issue and actions, under different scenarios, to minimize or prevent a crisis and ensure the safety of your loved one and other family members. The Family Safety Plan should be prepared in conjunction with the Family Emergency or Crisis Plan. Developing and practicing a Family Safety Plan is preventative, just like wearing a seatbelt. When, despite best efforts, a situation turns into an emergency, having a Family Crisis Plan is essential and is the last piece of your family's safety planning. Display your Family Safety Plan and Family Crisis Plan in a visible location.

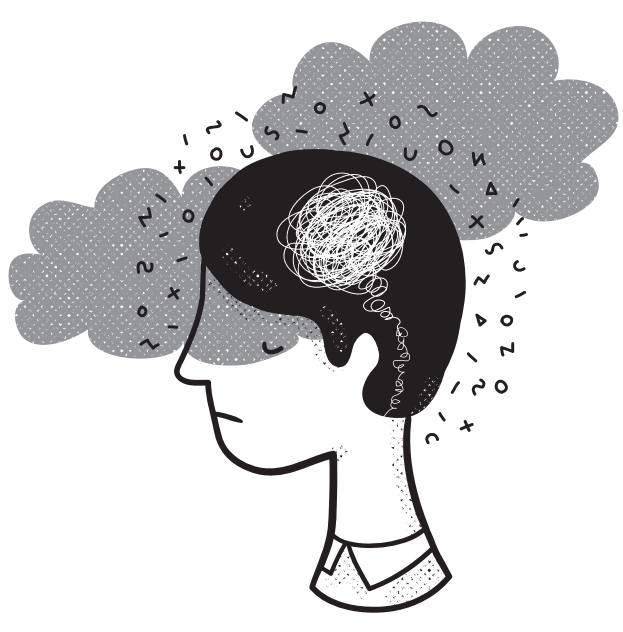
Keep a binder with all the backup materials you need readily available to all family members. Most importantly, practice it with all family members and keep it up to date!

\section{Tips for Creating a Family Safety Plan}

》Engage as many of your family members as possible in the process. Reach out to important friends and medical professionals for advice and input as well as a local mental health crisis team.

Each family member should agree that it is in everyone's best interests to calm episodes before they become out of control.

Explore strategies that have worked in the past to calm or diffuse a situation and consider new strategies that may be helpful. Discuss "what to do, if this were to happen."

Approach each other with an attitude of curiosity and respect; ask permission to offer opinions.

Use clear and succinct language. Keep it simple.

Review options, scenarios and strategies together and document their level of helpfulness.

Agree on what symptoms may look like from each of your perspectives without judgment or criticism. If your loved one perceives your observations as an attack, refrain from sharing them. However, document them in some form so that YOU remember when you observe these actions. 


\section{What to include in your Family Safety Plan and Binder}

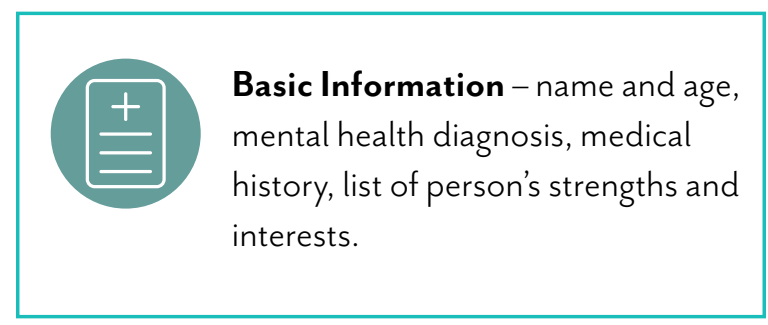

Behaviors - Early warning signs that
your loved one may be having
trouble, because if all family
members are aware of this, it can
help prevent a crisis. Include a list of
strategies that have worked to de-escalate
situations in the past and a list of things/people
that are likely to make the situation worse.
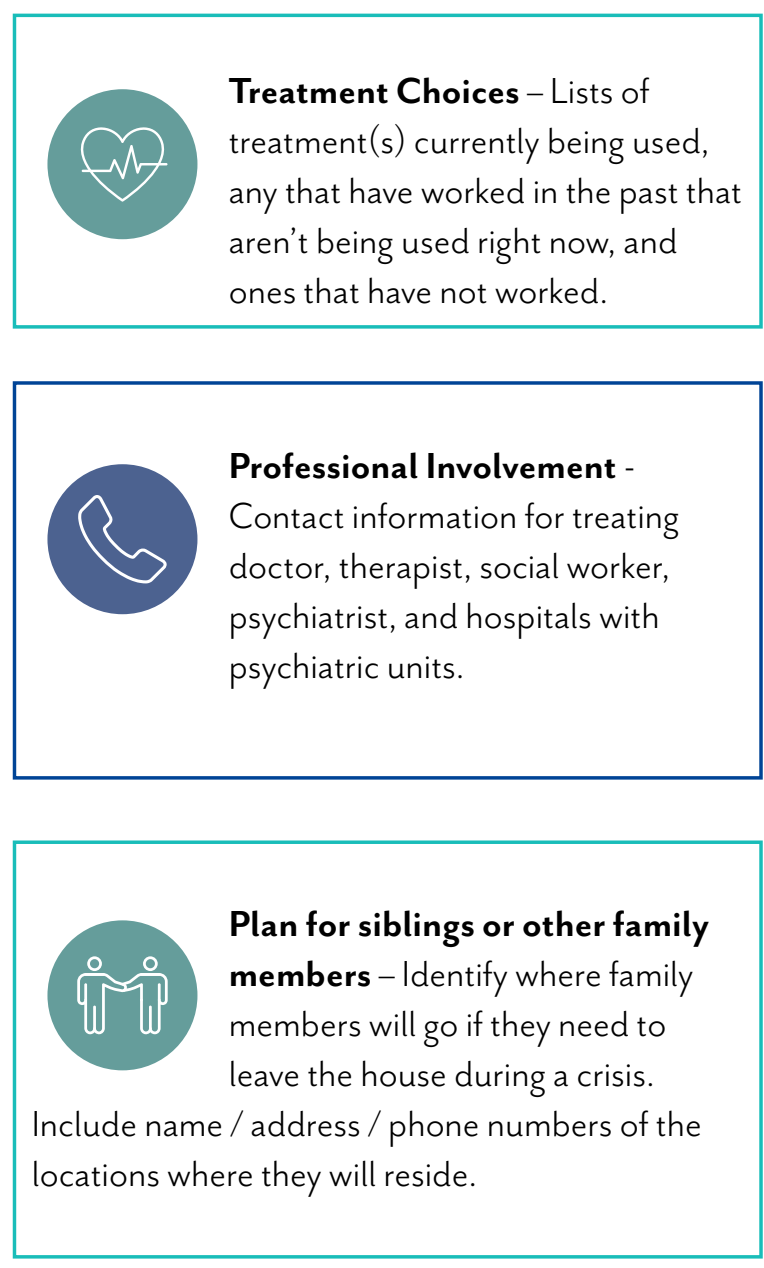
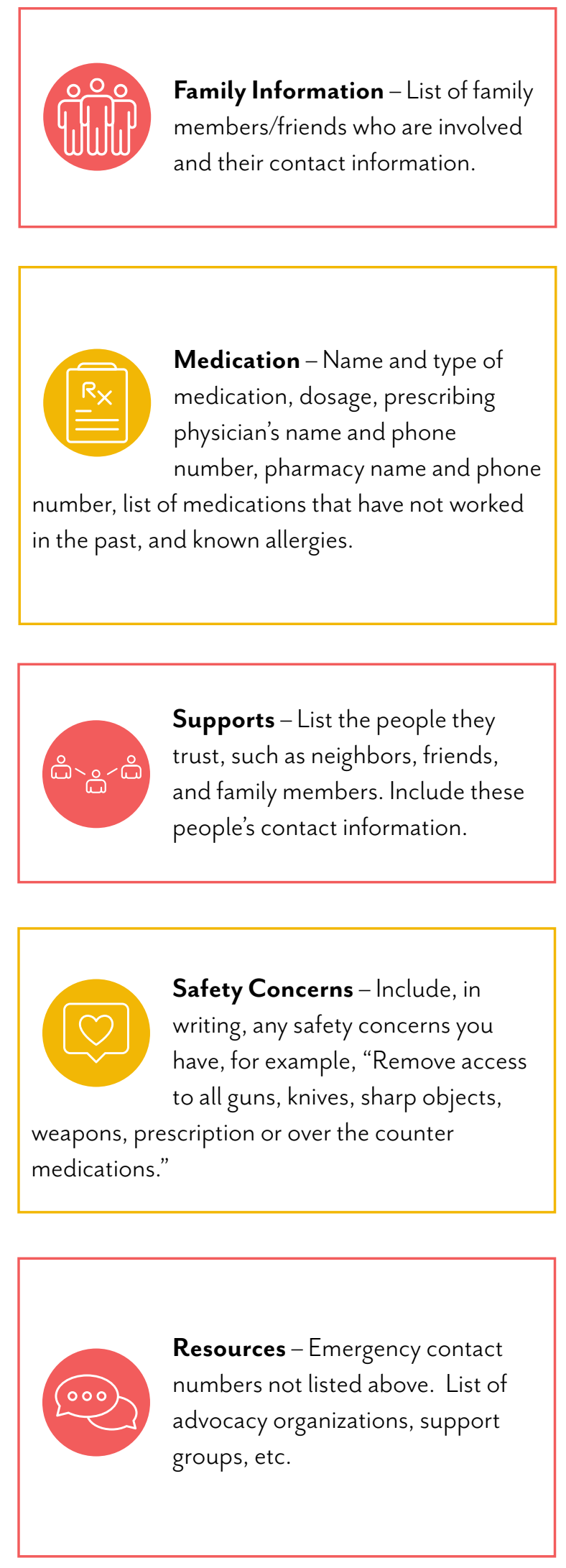


\section{Before a Crisis Occurs...}

»Contact your local police department and provide them with a copy of the Safety $\&$ Crisis Plans.

》 Talk with your loved one about the importance of signing Releases of Information for family members, therapists, and other members of their treatment team if hospitalized.

Consider obtaining power of attorney in advance, if appropriate.

In advance, learn the rights that you and your loved one have when they are at the emergency department or in an in-patient facility.

\section{Family Crisis Plan for Emergencies}

\section{CRISIS KIT}

$\square$ Keep a binder with past

history

$\square$ Snacks

$\square$ Things to soothe siblings/ children

$\square$ Change of clothes

$\square$ Basic hygiene supplies

》Let first responders know that this is a mental health crisis and request they respond without lights or sirens.

》Provide basic information to first responders including: name of loved one, where they are in the house, best ways to approach including any interests or topics to use to enable quick connections.

》Have Family Safety Plan Binder available with all advance directives.

\section{Additional Resources:}

Grow A Strong family, Inc. How To: Manage When Our Loved Ones Are Symptomatic:

https://growastrongfamily.org/wp-content/uploads/2018/10/Tip-sheetmanaging-symptoms.pdf

Grow A Strong family Inc. Defensive not Offensive-Brochure: https://growastrongfamily.org/wp-content/uploads/2018/10/Defensivenot-Offensive-Brochure.pdf

iSPARC Partnering with Families \& Other Natural Supports on Individualized Service Plans (ISPs):

https://escholarship.umassmed.edu/cgi/viewcontent.

cgi? article $=1128 \&$ context $=$ pib

iSPARC Linking Kids with Trauma to Evidence-Based Treatment:

https://escholarship.umassmed.edu/cgi/viewcontent.

cgi? article $=1139 \&$ context $=$ pib
Maine.gov Rights and Legal Issues - Sample Crisis Plan:

https://www.maine.gov/dhhs/samhs/mentalhealth/rights-legal/crisisplan/home.html

The Massachusetts Behavioral Health Partnership Crisis Planning Tools for Families: A Companion Guide for Providers: https:// www.masspartnership.com/pdf/Crisis-Planning-Tools_Guide_for_

ProvidersFinal.pdf

Mental Health First Aid:

https://www.mentalhealthfirstaid.org/

NAMI Being Prepared for a Crisis:

https://www.nami.org/Your-Journey/Family-Members-and-Caregivers/ Being-Prepared-for-a-Crisis

\section{Helplines and Support:}

SAMHSA Helpline - 1-800-985-5990

National Suicide Prevention line - 1-800-273-8255 and website: https://suicidepreventionlifeline.org

Crisis Text Line - Text "HOME" to 741741 to connect with a crisis counselor or visit https://www.crisistextline.org
The Trevor Project - Specializing in supporting the LGBTQ community, call 1-866-488-7386 or text "START" to 678-678

NAMI helpline - https://www.nami.org/help

NAMI support groups - https://www.nami.org/Support-Education/ Disaster Distress Helpline - 1-800-985-5990 or text "TalkWithUs" to 66746

Recommended Citation: Transitions to Adulthood Center for Research Family Advisory Board. (2020). Before a Mental Health Crisis Hits: Creating a Family Safety Plan. Worcester, MA: University of Massachusetts Medical School, Department of Psychiatry, Implementation Science and Practice Advances Research Center (iSPARC), Transitions to Adulthood Center for Research.

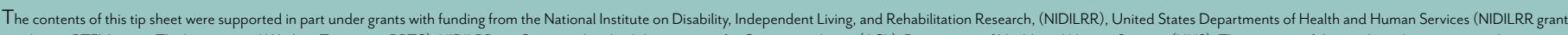

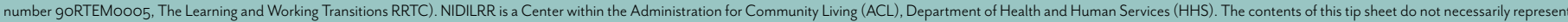
the policy of NIDILRR, ACL, or HHS and you should not assume endorsement by the Federal Government. 


\section{Grisis Plan}

Emergency Resource 1:

Emergency Resource 2:

Emergency Resource 3:
Phone:

Phone:

Phone:

This is a mental health emergency! Come without lights or sirens. We will meet you...

Our loved one's name is $\mathrm{S} / \mathrm{he}$ is in the house.

The best way to approach is:

His/her biggest fear is:

We have a copy of the Safety Plan, including all medications for you.

We have a copy of the Five Wishes* (advanced care directive).

If we need help from professionals, we will follow these steps (include how the children and other vulnerable family members will be taken care of):

1.

2.

3.

4.

5.

When will we think about going to the hospital? What type of behavior would make us consider doing this?

When will we think about calling 911? What type of behavior would make us consider doing this? 